Check for updates

Cite this: RSC Adv., 2019, 9, 5582

\title{
Mechanism and modeling of hexavalent chromium interaction with a typical black soil: the importance of the relationship between adsorption and reduction $\uparrow$
}

\begin{abstract}
Jia Zhang, ${ }^{a}$ Huilin Yin, ${ }^{\text {ab }}$ Samuel Barnie, ${ }^{a}$ Minghai Wei (iD *ab and Honghan Chen ${ }^{a}$
Black soils have a significant retention effect on the migration of $\mathrm{Cr}(\mathrm{vI})$ towards groundwater, and $\mathrm{Cr}(\mathrm{vI})$ adsorption and reduction are both involved in this process. However, the adsorption and reduction of $\mathrm{Cr}(\mathrm{VI})$ were always investigated separately in previous studies resulting in an unclear relationship between them. In this study, the adsorption and reduction kinetic processes of $\mathrm{Cr}(\mathrm{vl})$ by a typical black soil were separately investigated under different initial $\mathrm{Cr}(\mathrm{VI})$ concentrations $\left(40-400 \mathrm{mg} \mathrm{L}^{-1}\right)$ and $\mathrm{pH}$ conditions (3.5-7.0) by the means of desorption treatment, and the equilibrium relationship between aqueous and adsorbed $\mathrm{Cr}(\mathrm{VI})$ was innovatively established based on the kinetic data. It was found that under $\mathrm{pH} 5.7$ the adsorbed $\mathrm{Cr}(\mathrm{VI})$ content on soil particles was linearly correlated with the remaining $\mathrm{Cr}(\mathrm{vl})$ concentration in solution with time $\left(R^{2}=0.98\right)$, and the reduction rate of $\mathrm{Cr}(\mathrm{vI})$ in the reaction system was linearly correlated with the adsorbed $\mathrm{Cr}(\mathrm{VI})$ content on soil particles with time $\left(R^{2}=0.99\right)$. With $\mathrm{pH}$ decreasing from 7.0 to 3.5, the partition of $\mathrm{Cr}(\mathrm{VI})$ between solid and aqueous phases turned out to be of a non-linear nature, which can be fitted better by the Freundlich model. The retention of $\mathrm{Cr}(\mathrm{VI})$ by black soil was determined to follow the "adsorption-reduction" mechanism, where the $\mathrm{Cr}(\mathrm{VI})$ was first rapidly adsorbed onto the soil particles by a reversible adsorption reaction, and then the adsorbed $\mathrm{Cr}(\mathrm{VI})$ was gradually reduced into $\mathrm{Cr}(\mathrm{III})$. A two-step kinetic model was developed accordingly, and the experimental data were fitted much better by the two-step adsorption-reduction kinetic model $\left(R^{2}=0.89\right.$ on average) compared with the traditional first-order and second-order kinetic models $\left(R^{2}=0.66\right.$ and 0.76 on average respectively). This paper highlights the novel two step kinetic model developed based on the proposed "adsorption-reduction" mechanism of $\mathrm{Cr}(\mathrm{VI})$ retention by a typical black soil.
\end{abstract}

Received 1st October 2018

Accepted 7th February 2019

DOI: $10.1039 / c 8 \mathrm{ra0} 8154 a$

rsc.li/rsc-advances

\section{Introduction}

Hexavalent chromium $\mathrm{Cr}(\mathrm{vI})$ is an important industrial material, which is widely utilized in alloy, electroplating, leather tanning, dyeing and wood preservation. ${ }^{1}$ According to the Toxic Release Inventory from USEPA, 52600 tons of $\mathrm{Cr}$ has been released into the environment by 1762 industrial facilities. ${ }^{2}$ In China, the electroplating industry alone can generate 400 million tons of wastewater and 50 thousand tons of solid waste per year, ${ }^{3}$ and the instances of wastewater discharging into the environment directly or by the means of seepage pits have led to serious $\mathrm{Cr}(\mathrm{vI})$ contamination of soil and groundwater., ${ }^{4,5}$ As known, $\mathrm{Cr}(\mathrm{vI})$ is extremely toxic and carcinogenic to plants and

\footnotetext{
${ }^{a}$ Beijing Key Laboratory of Water Resources \& Environmental Engineering, China University of Geosciences, Beijing 100083, China. E-mail:wmh87@163.com ${ }^{b}$ Chinese Academy for Environmental Planning, China

$\dagger$ Electronic supplementary information (ESI) available. See DOI: $10.1039 / \mathrm{c} 8 \mathrm{ra} 08154 \mathrm{a}$
}

human beings, ${ }^{6,7}$ which is considered as one of the four top priority soil heavy metal contaminants of concern by United State Department of Defense. ${ }^{8-10}$

The soil layer has been found to have significant retention effect on the migration of $\mathrm{Cr}(\mathrm{vI})$ towards groundwater, and many investigations have focused on the topic of $\mathrm{Cr}(\mathrm{vI})$ adsorption by soils. ${ }^{11,12}$ It has been extensively reported that $\mathrm{Cr}(\mathrm{vI})$ anions $\left(\mathrm{Cr}_{2} \mathrm{O}_{7}{ }^{2-}, \mathrm{HCrO}_{4}{ }^{-}\right.$and $\left.\mathrm{CrO}_{4}{ }^{2-}\right)$ tend to be bound to positively charged soil particles by forming inner-sphere (specific adsorption) or outer-sphere (non-specific adsorption) complexes, ${ }^{8}$ and the adsorption of $\mathrm{Cr}(\mathrm{vI})$ by soil is mainly influenced by $\mathrm{pH}$ condition, electrolyte species, inorganic minerals (e.g. iron oxides, aluminum oxides, manganese oxides, and clay) and organic matters (e.g. humus). ${ }^{2,13,14}$ In addition, substantial attentions were focused on the kinetic and thermodynamic aspects of $\mathrm{Cr}(\mathrm{vI})$ adsorption by soil in previous studies. Notably, the adsorption of $\mathrm{Cr}(\mathrm{vr})$ by soils was quite different from the other heavy metal cations, such as $\mathrm{Pb}^{2+}, \mathrm{Cu}^{2+}$ and $\mathrm{Cd}^{2+}$. The adsorption of heavy metal cations by soils can 
generally reach equilibrium state within hours, however, the adsorption of $\mathrm{Cr}(\mathrm{vI})$ by soils always go through a slow adsorption process (even still proceeding after 180 days),${ }^{15}$ which always led to a poor fitting performance of the kinetic data by traditional first-order or second-order kinetic models.

$\mathrm{Cr}(\mathrm{vI})$ is of strong oxidation property especially under acidic condition, and can be reduced into $\mathrm{Cr}$ (III) gradually by inorganic or organic electron donors in the soil environment. ${ }^{\mathbf{1 6}, 17} \mathrm{Cr}$ (III) mainly exists in cations or colloidal precipitate, such as $\mathrm{Cr}^{3+}$, $\mathrm{CrOH}^{2+}, \mathrm{Cr}(\mathrm{OH})_{2}{ }^{+}$, and $\mathrm{Cr}(\mathrm{OH})_{3}$, and can be readily adsorbed or precipitate on soil particles. Additionally, $\mathrm{Cr}(\mathrm{III})$ is less harmful compared with $\mathrm{Cr}(\mathrm{vI})$, which even act as an essential trace element for human bodies, and thus reducing $\mathrm{Cr}(\mathrm{vI})$ into less mobile and toxic $\mathrm{Cr}$ (III) is regarded as one of the most effective strategies for $\mathrm{Cr}(\mathrm{vI})$ contaminated soil and groundwater remediation. ${ }^{\mathbf{1 8 - 2 1}}$

The natural reduction of $\mathrm{Cr}(\mathrm{vI})$ on soil particles is mainly influenced by $\mathrm{pH}$ condition, redox potential, and inorganic and organic electron donors. ${ }^{22,23}$ For $\mathrm{Cr}(\mathrm{vI})$ adsorption, $\mathrm{pH}$ condition mainly determines the soil particle variable charge character according to zero point of charge (ZPC), but for $\mathrm{Cr}(\mathrm{vI})$ reduction, $\mathrm{pH}$ condition mainly determines the proton concentration, which is a necessary element participating in this reaction. Additionally, soil organic matters (SOM) are considered to act as the main electron donors for $\mathrm{Cr}(\mathrm{vI})$ reduction in soil environment, ${ }^{24,25}$ but the reduction rate of $\mathrm{Cr}(\mathrm{vI})$ by SOM is much slower compared with inorganic electron donors, such as Fe(II) and $\mathrm{S}$ (II), and that is why the real equilibrium state of $\mathrm{Cr}(\mathrm{vI})$ adsorption by soil is almost impossible to be reached within a short time except for that $\mathrm{Cr}(\mathrm{VI})$ is exhausted, which may be account for the slow adsorption process of $\mathrm{Cr}(\mathrm{vI})$ by soils.

As can be seen, the retention of $\mathrm{Cr}(\mathrm{vI})$ by soil includes adsorption and reduction, and both of them are of great significance for $\mathrm{Cr}(\mathrm{vI})$ retention in the soil. The adsorption determines the macroscopic retention effect of $\mathrm{Cr}(\mathrm{vI})$ migration, while the reduction determines the toxicity (environmental risk) and stability (leaching potential) of $\mathrm{Cr}^{8}$ These two processes interplay with each other, neither of which should be ignored. However, the adsorption and reduction of $\mathrm{Cr}(\mathrm{vI})$ were always investigated separately in previous studies resulting from the unclear relationship between them. ${ }^{26-28}$ Therefore, it is urgent to establish a quantitative relationship between adsorption and reduction of $\mathrm{Cr}(\mathrm{v})$ in soil, which is the key point to reveal the underlying mechanism of $\mathrm{Cr}(\mathrm{vI})$ retention by soils, and this is of vital importance for the prediction and assessment of $\mathrm{Cr}(\mathrm{vI})$ migration/transformation and environmental risk in soils and sediments.

In this study, the adsorption and reduction processes of $\mathrm{Cr}(\mathrm{vI})$ by a typical black soil were investigated respectively under different initial $\mathrm{Cr}(\mathrm{vI})$ concentration $\left(40-400 \mathrm{mg} \mathrm{L}^{-1}\right)$ and $\mathrm{pH}$ (3.5-7.0) conditions by the means of desorption treatment. The main purposes of this study were to (1) reveal the partition characteristic of $\mathrm{Cr}(\mathrm{vI})$ adsorption from aqueous phase to soil solid phase, (2) establish the quantitative relationship between adsorption and reduction of $\mathrm{Cr}(\mathrm{vI})$ in the typical black soil, and (3) simulate the experimental data by the kinetic model developed according to the proposed "adsorption-reduction" mechanism of $\mathrm{Cr}(\mathrm{vI})$ retention by the typical black soil.

\section{Materials and methods}

\subsection{Materials}

The stock solution of $\mathrm{Cr}(\mathrm{vI})$ and $\mathrm{NaCl}$ were prepared by the chemicals of $\mathrm{K}_{2} \mathrm{Cr}_{2} \mathrm{O}_{7}$ and $\mathrm{NaCl}$ respectively, and both of these chemicals were obtained from Sinopharm Chemical Reagent Co., Ltd with analytical purity (AR). The working solution was prepared by diluting certain volumes of $\mathrm{Cr}(\mathrm{VI})$ and $\mathrm{NaCl}$ stock solutions with deionized water just before it was to be used. The final concentration of $\mathrm{Cr}(\mathrm{vI})$ in the working solutions ranged from 40 to $400 \mathrm{mg} \mathrm{L}^{-1}$, and the concentration of $\mathrm{NaCl}$ was $0.01 \mathrm{M}$, which acted as the background electrolyte.

The used black soil sample was obtained from an undisturbed area located at the northeast of China $\left(43^{\circ} 18^{\prime} 36^{\prime \prime} \mathrm{N}\right.$, $128^{\circ} 23^{\prime} 26^{\prime \prime} \mathrm{E}$ ), where is located at one of the three major black soil regions worldwide (the other two are the great plains of Ukraine and the Mississippi River basin of America, respectively). This black soil sample can be classified as Mollisol soil according to USDA soil classification system, and it is the typical black soil in the region of Northeast China. The location, landform, climate and vegetation can be found in our previous published paper. ${ }^{29}$ The surface soil within the depth of $30 \mathrm{~cm}$ was sampled after the topsoil containing substantial plant roots had been removed. The soil sample was air-dried and ground, and then was passed through a 100-mesh sieve.

\subsection{Characterization of the black soil sample}

The $\mathrm{pH}$ of the black soil sample was determined by mixing soil with $1 \mathrm{M} \mathrm{KCl}$ solution in the solid to liquid ratio of $1: 2.5(\mathrm{w}: \mathrm{v})$, and the $\mathrm{pH}$ value was measured after stirring the mixture for 5 min and standing for $3 \mathrm{~h}$. The zero point of charge (ZPC) was determined by the method described elsewhere. ${ }^{30}$ The organic matter content of the soil sample was determined by the Walkley-Black procedure. ${ }^{31}$ The chemical composition of the soil sample was determined by X-ray Fluorescence spectroscopy (XRF). The mineral composition of the soil sample was characterized by X-ray diffraction (XRD) on a machine of Rigaku D/ MAX-rA.

The $\mathrm{pH}_{\mathrm{KCl}}$ of the soil sample was determined to be 4.6 , and the content of organic matter was determined to be $11.64 \%$. The $\mathrm{SiO}_{2}$ was determined to be the main constituent of the soil sample (44.36\%), and the contents of $\mathrm{Al}_{2} \mathrm{O}_{3}$ and $\mathrm{Fe}_{2} \mathrm{O}_{3}$ were determined to be $16.52 \%$ and $6.79 \%$ respectively. The other inorganic compositions contents were all under $3 \%$.

\subsection{Sorption experiment}

In order to reveal the underlying mechanism of $\mathrm{Cr}(\mathrm{vI})$ retention by the soil sample under various conditions, the sorption experiment was conducted under different initial $\operatorname{Cr}(\mathrm{vI})$ concentrations and $\mathrm{pH}$ values. In the experiment under different initial $\mathrm{Cr}(\mathrm{vI})$ concentrations, $2 \mathrm{~g}$ black soil samples were added into a series of $40 \mathrm{~mL}$ amber bottles, and $20 \mathrm{~mL}$ working solutions with $\mathrm{Cr}(\mathrm{vI})$ concentrations of 40, 100, 250 and $400 \mathrm{mg} \mathrm{\textrm {L } ^ { - 1 }}$ were added into the bottles as well. The working solutions contained $0.01 \mathrm{M} \mathrm{NaCl}$ as background electrolyte, and the initial $\mathrm{pH}$ was adjusted to 5.7 by adding $0.1 \mathrm{M} \mathrm{HCl}$ and 
$\mathrm{NaOH}$ solutions. All the above experiments were performed in triplicate, and a blank group (without $\mathrm{Cr}(\mathrm{vI})$ ) and a control group (without soil sample) were set for each time step. The bottles were put into the shaker incubator, and shaken at $175 \mathrm{rpm}$ at $25{ }^{\circ} \mathrm{C}$. At given time intervals, a batch of bottles was taken out from the shaker incubator, and then centrifuged at $3000 \mathrm{rpm}$ for $10 \mathrm{~min}$. The supernatant was filtrated with $0.45 \mu \mathrm{m}$ membrane, and the $\mathrm{Cr}(\mathrm{vI})$ and $\mathrm{Cr}(\mathrm{T})$ concentration in the filtrate were determined by the methods of UV spectrophotometry (SHIMADZU UV-1800) and ICP-OES (SPECBIUE) respectively. The Cr(III) concentration in solution was determined by the difference between the concentrations of $\operatorname{Cr}(\mathrm{T})$ and $\mathrm{Cr}(\mathrm{vI})$. The $\mathrm{pH}$ value and total organic carbon (TOC) in solution were measured simultaneously.

In the experiment under different initial $\mathrm{pH}$ values, the same amount of soil samples were added into a series of amber bottles as well, and then $20 \mathrm{~mL}$ working solutions with initial pH of 3.5, 5.7 and 7.0 were added into the bottles. The initial $\mathrm{Cr}(\mathrm{vI})$ concentration of the working solutions was $250 \mathrm{mg} \mathrm{L}^{-1}$. The other experiment conditions and procedures were same with those conducted under different initial $\mathrm{Cr}(\mathrm{vI})$ concentrations.

In order to differentiate the adsorption and reduction processes of $\mathrm{Cr}(\mathrm{VI})$ in the reaction system, the amount of $\mathrm{Cr}(\mathrm{vI})$ adsorbed on the surface of soil particles must be determined. Considering that the specific and non-specific adsorbed $\mathrm{Cr}(\mathrm{vI})$ may both exist on the surface of soil particles at the same time, and the background electrolyte solution has almost no desorption effect on the specific adsorbed $\mathrm{Cr}(\mathrm{vI}), \mathrm{NaOH}$ solution was used for the desorption of both specific and non-specific adsorbed $\mathrm{Cr}(\mathrm{vI})$ on soil particles in this experiment, which is considered to be able to desorb the specific adsorbed $\mathrm{Cr}(\mathrm{vI})$ by ligand exchange. The soil sample after reacting with $\mathrm{Cr}(\mathrm{vI})$ were collected by centrifuging (the centrifugation procedure mentioned above), and $20 \mathrm{~mL} 0.5 \mathrm{M} \mathrm{NaOH}$ solution was added in the bottle. ${ }^{32}$ The mixture was shaken in the shaker incubator at $175 \mathrm{rpm}$ at $25{ }^{\circ} \mathrm{C}$ for $12 \mathrm{~h}$, and then centrifuged at $3000 \mathrm{rpm}$ for $10 \mathrm{~min}$. The supernatant was filtrated with $0.45 \mu \mathrm{m}$ membrane, and the concentrations of $\operatorname{Cr}(\mathrm{vI})$ and $\operatorname{Cr}(\mathrm{T})$ were determined by the same methods mentioned above. Considering that the color of dissolved humus in the alkaline solution may influence the determination of $\mathrm{Cr}(\mathrm{vI})$ concentration by the method of UV spectrophotometry, the blank control of deionized water was replaced by the same dosage of alkaline solution, and the color-developing agent of 1,5-diphenylcarbazide was replaced by the same dosage of deionized water. The above procedures were repeated three times until the concentration of $\mathrm{Cr}(\mathrm{vI})$ in alkaline solution turned to be very low, and then the $\mathrm{Cr}(\mathrm{vI})$ concentrations from the three times of determination were added up to calculate the $\mathrm{Cr}(\mathrm{vI})$ content on the soil sample.

\subsection{FTIR characterization of humic acid extracted from the black soil}

Humic acid (HA) was extracted from the soil samples with $0.5 \mathrm{M}$ $\mathrm{NaOH}$ solution for $12 \mathrm{~h}$, and the suspensions were centrifuged at $4500 \mathrm{rpm}$ for $15 \mathrm{~min}$ to obtain the supernatant. The $\mathrm{pH}$ of the supernatant was adjusted to 1 by adding $6 \mathrm{M} \mathrm{HCl}$ to make HA precipitated, and the suspensions were centrifuged at $4500 \mathrm{rpm}$ for $15 \mathrm{~min}$ to obtain the HA samples. The HA samples were freeze-dried, and characterized by an IR spectrometer (Bruker LUMOS, Germany) at room temperature. The samples were uniformly mixed with dried $\mathrm{KBr}$ powder at mass ratio of $1: 200$. Each spectrum was obtained after 64 scans with $2 \mathrm{~cm}^{-1}$ resolution.

\section{Results and discussion}

\section{1 $\mathrm{Cr}(\mathrm{v})$ retention processes}

3.1.1 Variation of $\mathrm{Cr}$ concentration in aqueous phase. The concentration variations of $\mathrm{Cr}(\mathrm{vI})$ and $\mathrm{Cr}(\mathrm{T})$ in solution under different initial $\mathrm{Cr}(\mathrm{vI})$ concentration conditions are shown in Fig. 1. As indicated, a rapid decrease in $\mathrm{Cr}(\mathrm{vI})$ concentration in solution within $5 \mathrm{~d}$ was observed in all experiments, followed by a slower constant decline since $5 \mathrm{~d}$ to $240 \mathrm{~d}$. Considering that the zero point of charge (ZPC) of the soil sample is 2.49 (Fig. S1 $\dagger$ ), the surface of soil particles was negatively charged under this experiment $\mathrm{pH}$ condition (5.7), therefore the initial rapid decrease in the concentration of $\mathrm{Cr}(\mathrm{vI})$ anion more tended to be induced by the driving force of molecular diffusion and complexation (specific adsorption) instead of electrostatic attraction (non-specific adsorption). The decrease of $\operatorname{Cr}(\mathrm{T})$ concentration in solution implied that $\mathrm{Cr}(\mathrm{vI})$ was indeed adsorbed onto soil particles from aqueous phase. The difference between $\mathrm{Cr}(\mathrm{T})$ and $\mathrm{Cr}(\mathrm{vI})$ concentration can be attributed to the concentration of $\mathrm{Cr}$ (III) in solution, and it can be seen that the equilibrium $\mathrm{Cr}$ (III) concentration in solution increased with initial $\mathrm{Cr}(\mathrm{vI})$ concentration increasing, which implied that the reduction of $\mathrm{Cr}(\mathrm{vI})$ to $\mathrm{Cr}(\mathrm{III})$ did occur in this reaction system.

The $\mathrm{pH}$ in all reaction systems increased with time as shown in Fig. $\mathrm{S} 2, \uparrow$ and the variation amplitudes decreased with initial $\mathrm{Cr}(\mathrm{vI})$ concentration resulting from the buffering effect of $\mathrm{Cr}(\mathrm{vI})$ anions. The TOC concentration in solution increased with time

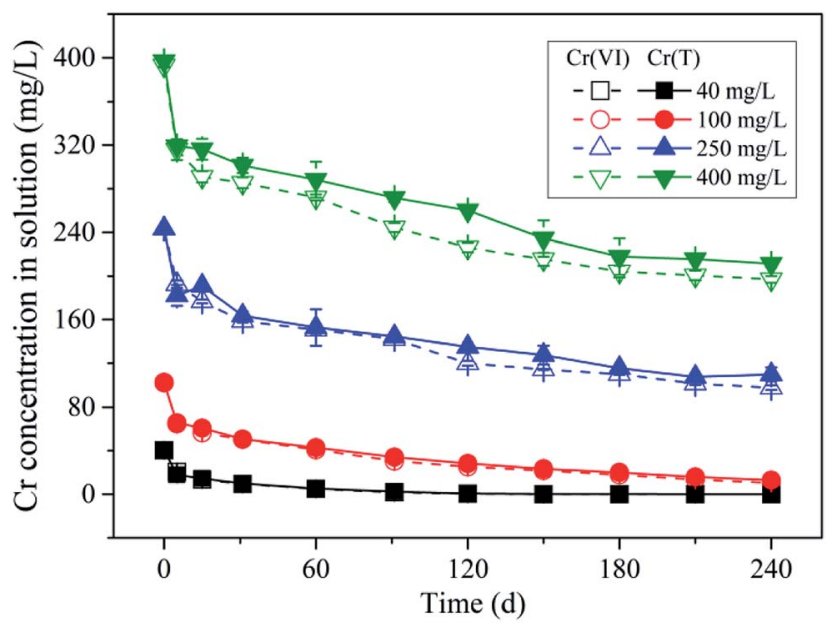

Fig. 1 Concentration variation of $\mathrm{Cr}(\mathrm{VI})$ and $\mathrm{Cr}(\mathrm{T})$ in solution with time under different initial $\mathrm{Cr}(\mathrm{VI})$ concentration conditions. Initial $\mathrm{Cr}(\mathrm{VI})$ concentration are $400,250,100$, and $40 \mathrm{mg} \mathrm{L}^{-1}$ respectively; initial $\mathrm{pH}$ is 5.7; background electrolyte is $0.01 \mathrm{M} \mathrm{NaCl} ; 2 \mathrm{~g}$ soil sample is contained in $20 \mathrm{~mL}$ solutions. Error bars are SEM $(n=3)$. 
as well resulting from soil organic matter (SOM) dissolution (Fig. S3 $\uparrow$ ), however, the variation amplitudes increased with initial $\mathrm{Cr}(\mathrm{vI})$ concentration, which is in contrast with the $\mathrm{pH}$ trend. Notably, the lower equilibrium $\mathrm{pH}$ condition resulting from the higher initial $\mathrm{Cr}(\mathrm{vI})$ concentration ought to be unfavorable for the dissolution of SOM (such as humic acid), therefore, the abnormal occurrence of the higher TOC concentration under lower $\mathrm{pH}$ condition might be induced by the oxidation of SOM by $\mathrm{Cr}(\mathrm{vI})$, where lower molecular weight SOM with higher solubility might be produced by SOM oxidative decomposition. Additionally, a positive correlation was found between the concentrations of TOC and $\mathrm{Cr}(\mathrm{III})$ in solution (Fig. S4†), which can be used to interpret the higher $\mathrm{Cr}(\mathrm{III})$ concentration in solution under higher initial $\mathrm{Cr}(\mathrm{VI})$ concentration condition resulting from the high solubility of dissolved organic matter (DOM) and Cr(III) complex.

3.1.2 Variation of $\mathrm{Cr}$ content on solid phase. As mentioned above, the reduction of adsorbed $\mathrm{Cr}(\mathrm{vI})$ was speculated to occur on soil particles, therefore, in order to clarify $\mathrm{Cr}$ valence state variation on solid phase, a desorption experiment was conducted to determine adsorbed $\mathrm{Cr}(\mathrm{vI})$ content. The content variations of $\mathrm{Cr}(\mathrm{VI})$ and $\mathrm{Cr}(\mathrm{III})$ on soil particles under different initial $\mathrm{Cr}(\mathrm{vr})$ concentration in solution are shown in Fig. 2. As can be seen, rapid increases of $\mathrm{Cr}(\mathrm{VI})$ and $\mathrm{Cr}(\mathrm{III})$ contents were observed within $5 \mathrm{~d}$, and the increase of $\mathrm{Cr}$ (III) content was much more significant than that of $\mathrm{Cr}(\mathrm{VI})$. This implied that under this experimental condition majority of the $\mathrm{Cr}(\mathrm{vI})$ adsorbed onto soil particles from solution was reduced into $\mathrm{Cr}(\mathrm{III})$, and only a small part of them still persisted on soil particles in the adsorbed state. Throughout the experiment, the content of $\mathrm{Cr}(\mathrm{III})$ on solid phase kept increasing on the whole, however, a slight increase of $\mathrm{Cr}(\mathrm{vr})$ content on solid phase was observed from 5 to $30 \mathrm{~d}$ followed by a continuous declination till the end. The adsorbed $\mathrm{Cr}(\mathrm{vr})$ was speculated to be an intermediate state of $\mathrm{Cr}(\mathrm{vr})$ for its reduction on soil particles. The accumulation of adsorbed $\mathrm{Cr}(\mathrm{vI})$

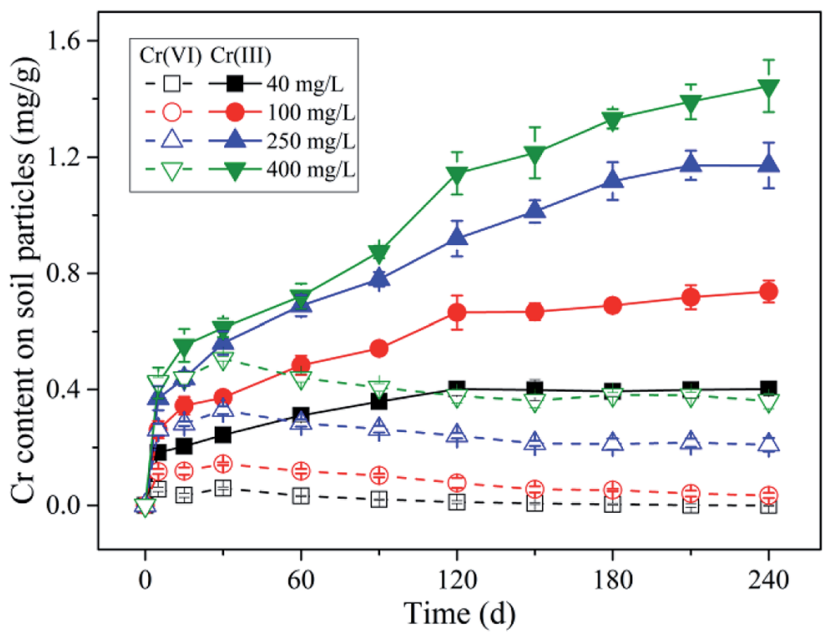

Fig. 2 Content variation of $\mathrm{Cr}(\mathrm{VI})$ and $\mathrm{Cr}(\mathrm{III})$ on soil particles with time under different initial $\mathrm{Cr}(\mathrm{VI})$ concentration conditions. Initial $\mathrm{Cr}(\mathrm{VI})$ concentration are $400,250,100$, and $40 \mathrm{mg} \mathrm{L}^{-1}$ respectively; initial $\mathrm{pH}$ is 5.7; background electrolyte is $0.01 \mathrm{M} \mathrm{NaCl} ; 2 \mathrm{~g}$ soil sample is contained in $20 \mathrm{~mL}$ solutions. Error bars are SEM $(n=3)$. on soil particles at initial stage $(0-30 \mathrm{~d})$ was supposed to be induced by the higher adsorption rate of $\mathrm{Cr}(\mathrm{vI})$ from aqueous to solid phase compared with the reduction rate of $\mathrm{Cr}(\mathrm{vI})$ on solid phase, and the decreasing of adsorbed $\mathrm{Cr}(\mathrm{vI})$ on soil particles during later stage (30-240 d) was supposed to be induced by the lower adsorption rate of $\mathrm{Cr}(\mathrm{vI})$ compared with $\mathrm{Cr}(\mathrm{vI})$ reduction rate on solid phase.

\section{$3.2 \mathrm{pH}$ effect on $\mathrm{Cr}(\mathrm{vI})$ retention processes}

3.2.1 $\mathrm{pH}$ effect on $\mathrm{Cr}$ concentration variation in aqueous phase. The variations of $\mathrm{Cr}(\mathrm{vI})$ and $\operatorname{Cr}(\mathrm{T})$ concentration in solution under different initial $\mathrm{pH}$ conditions are shown in Fig. 3. As indicated, $\mathrm{Cr}(\mathrm{vI})$ concentration in solution decreased sharply within $5 \mathrm{~d}$, and the decrease amplitude increased with $\mathrm{pH}$ decreasing. As mentioned above, ZPC of the soil sample is 2.49, therefore, the electrostatic repulsion between $\mathrm{Cr}(\mathrm{VI})$ anions and negative-charged soil particles decreased with $\mathrm{pH}$ decreasing, resulting in a higher adsorption rate of $\mathrm{Cr}(\mathrm{vI})$. After $5 \mathrm{~d}, \mathrm{Cr}(\mathrm{vI})$ concentration in solution decreased in various extents under different $\mathrm{pH}$ conditions, and $\mathrm{Cr}(\mathrm{vI})$ removal rate increased with $\mathrm{pH}$ decreasing.

Throughout the experiment, the $\mathrm{pH}$ kept almost constant with a slight increasing, resulting from the proton consumption by $\mathrm{Cr}(\mathrm{vI})$ reduction (Fig. S5 $\dagger$ ). Meanwhile, the TOC in solution decreased with $\mathrm{pH}$ decreasing (Fig. S6 $\dagger$ ), due to the poor solubility of SOM under strong acidic condition (such as humic acid). It was worthy to note that the $\mathrm{Cr}(\mathrm{III})$ concentration in solution increased with $\mathrm{pH}$ increasing, however, in theory $\mathrm{Cr}$ (III) cations were supposed to be much more soluble under acidic conditions than neutral conditions. Considering that the TOC concentration under $\mathrm{pH} 7.0\left(110 \mathrm{mg} \mathrm{C} \mathrm{L}{ }^{-1}\right)$ was much higher than that under $\mathrm{pH} 3.5\left(51 \mathrm{mg} \mathrm{C} \mathrm{L}^{-1}\right)$, and the positive correlation between the concentrations of TOC and $\mathrm{Cr}(\mathrm{III})$ in solution under different $\mathrm{pH}$ conditions as well (Fig. S7 $\dagger$ ), it can be further confirmed that the occurrence of high $\mathrm{Cr}(\mathrm{III})$ concentration in

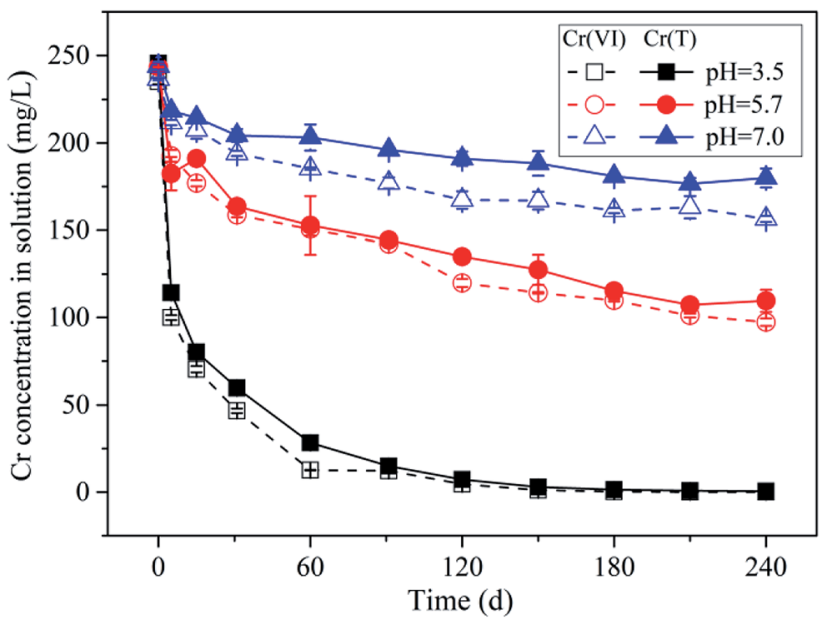

Fig. $3 \mathrm{pH}$ effect on concentration variation of $\mathrm{Cr}(\mathrm{VI})$ and $\mathrm{Cr}(\mathrm{T})$ in solution with time. Initial $\mathrm{pH}$ are $3.5,5.7$, and 7.0 respectively; initial $\mathrm{Cr}(\mathrm{VI})$ concentration is $250 \mathrm{mg} \mathrm{L}^{-1}$; background electrolyte is $0.01 \mathrm{M}$ $\mathrm{NaCl} ; 2 \mathrm{~g}$ soil sample is contained in $20 \mathrm{~mL}$ solutions. Error bars are $\operatorname{SEM}(n=3)$. 
solution under neutral condition was mainly related to the formation of complex between $\mathrm{Cr}$ (III) cations and DOM.

3.2.2 $\mathrm{pH}$ effect on $\mathrm{Cr}$ content variation on solid phase. The variations of $\mathrm{Cr}(\mathrm{VI})$ and $\mathrm{Cr}(\mathrm{III})$ content on soil particles under different initial $\mathrm{pH}$ conditions are shown in Fig. 4. As indicated, the content of reduced $\mathrm{Cr}(\mathrm{III})$ was much more significant compared with adsorbed $\mathrm{Cr}(\mathrm{vI})$ on solid phase, and the contents of adsorbed $\mathrm{Cr}(\mathrm{VI})$ and reduced $\mathrm{Cr}(\mathrm{III})$ both increased with $\mathrm{pH}$ decreasing. The contents of adsorbed $\mathrm{Cr}(\mathrm{vI})$ on solid phase kept decreasing till the end under all experimental $\mathrm{pH}$ conditions. Meanwhile, the reduced $\mathrm{Cr}(\mathrm{III})$ contents on solid phase increased continuously with almost a constant rate under $\mathrm{pH}$ 5.7 and 7.0, however, under $\mathrm{pH} 3.5$ the reduced $\mathrm{Cr}$ (III) content increased rapidly during initial stage $(0-30 \mathrm{~d})$ followed by a slow increasing till the end. The reason is that under $\mathrm{pH} 3.5$ the $\mathrm{Cr}(\mathrm{vI})$ concentration in solution has been quite low by $30 \mathrm{~d}$, and thus the reduction rate was limited. In contrast, substantial $\mathrm{Cr}(\mathrm{vI})$ still remained in the reaction system by the end of the experiment under $\mathrm{pH} 5.7$ and 7.0, and hence the reduction rate of $\mathrm{Cr}(\mathrm{vI})$ can be almost constant.

\subsection{Adsorption-reduction mechanism of $\mathrm{Cr}(\mathrm{vr})$ retention}

3.3.1 $\mathrm{Cr}(\mathrm{vi})$ adsorption by the black soil. The isotherm adsorption models, such as Langmuir and Freundlich model, are widely utilized for the data fitting of heavy metal adsorption by various sorbents, ${ }^{33}$ however, it is questionable whether these models are suitable to be directly used for the description of $\mathrm{Cr}(\mathrm{vI})$ adsorption by the sorbents containing significant electron donors. Because the adsorption process of $\mathrm{Cr}(\mathrm{vI})$ by black soil was accompanied by $\mathrm{Cr}(\mathrm{VI})$ reduction, the equilibrium state of $\mathrm{Cr}(\mathrm{vI})$ adsorption/desorption between aqueous and solid phases was almost impossible to obtained from the continuous variation of $\mathrm{Cr}(\mathrm{vI})$ concentration in solution. ${ }^{34}$ Considering that the reduced $\mathrm{Cr}(\mathrm{III})$ on soil particles cannot participate in the reversible reaction of $\mathrm{Cr}(\mathrm{vI})$ adsorption-desorption any more,

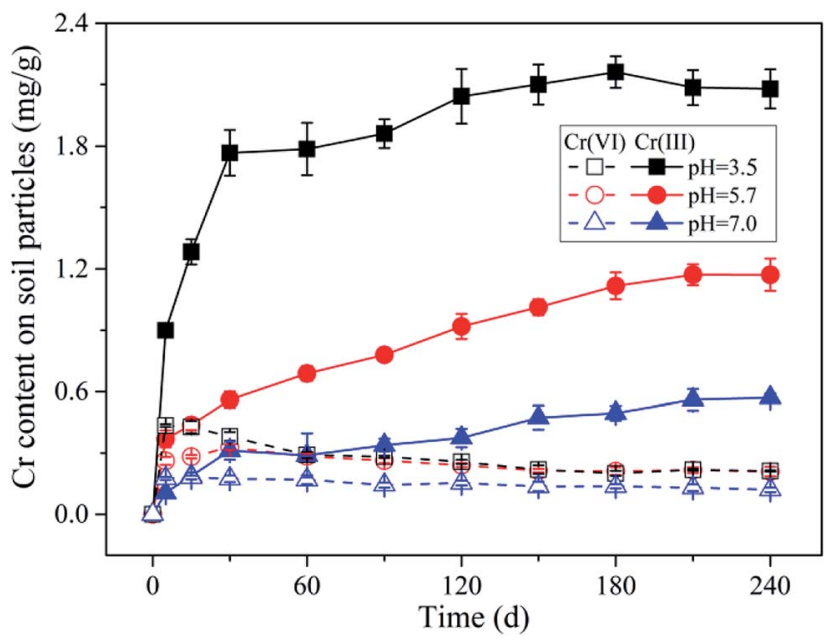

Fig. $4 \mathrm{pH}$ effect on content variation of $\mathrm{Cr}(\mathrm{VI})$ and $\mathrm{Cr}(\mathrm{III})$ on soil particles with time. Initial $\mathrm{pH}$ are $3.5,5.7$, and 7.0 respectively; initial $\mathrm{Cr}(\mathrm{VI})$ concentration is $250 \mathrm{mg} \mathrm{L}^{-1}$; background electrolyte is $0.01 \mathrm{M}$ $\mathrm{NaCl} ; 2 \mathrm{~g}$ soil sample is contained in $20 \mathrm{~mL}$ solutions. Error bars are $\operatorname{SEM}(n=3)$. the adsorption and reduction processes of $\mathrm{Cr}(\mathrm{vI})$ should be analyzed separately. Consequently, in order to verify whether the adsorbed $\mathrm{Cr}(\mathrm{vI})$ and aqueous $\mathrm{Cr}(\mathrm{vI})$ followed certain partition law, correlations were established between the remaining $\mathrm{Cr}(\mathrm{vI})$ concentration in solution and adsorbed $\mathrm{Cr}(\mathrm{vI})$ content on soil particles under different initial $\mathrm{Cr}(\mathrm{vI})$ concentrations and $\mathrm{pH}$ conditions (Fig. 5), and the data were obtained from above kinetic experiments at different reaction time.

As indicated in Fig. 5a, under different initial $\mathrm{Cr}(\mathrm{vI})$ concentration conditions, the adsorbed $\mathrm{Cr}(\mathrm{vI})$ was found to be positively correlated with the remaining $\mathrm{Cr}(\mathrm{vI})$ in solution in the same linear zone (the grey band), which implied that a nearlinear partition rule was in charge of the $\mathrm{Cr}(\mathrm{vI})$ adsorption process. With time, the data points of different initial $\mathrm{Cr}(\mathrm{vI})$ concentration conditions all kept moving towards the original
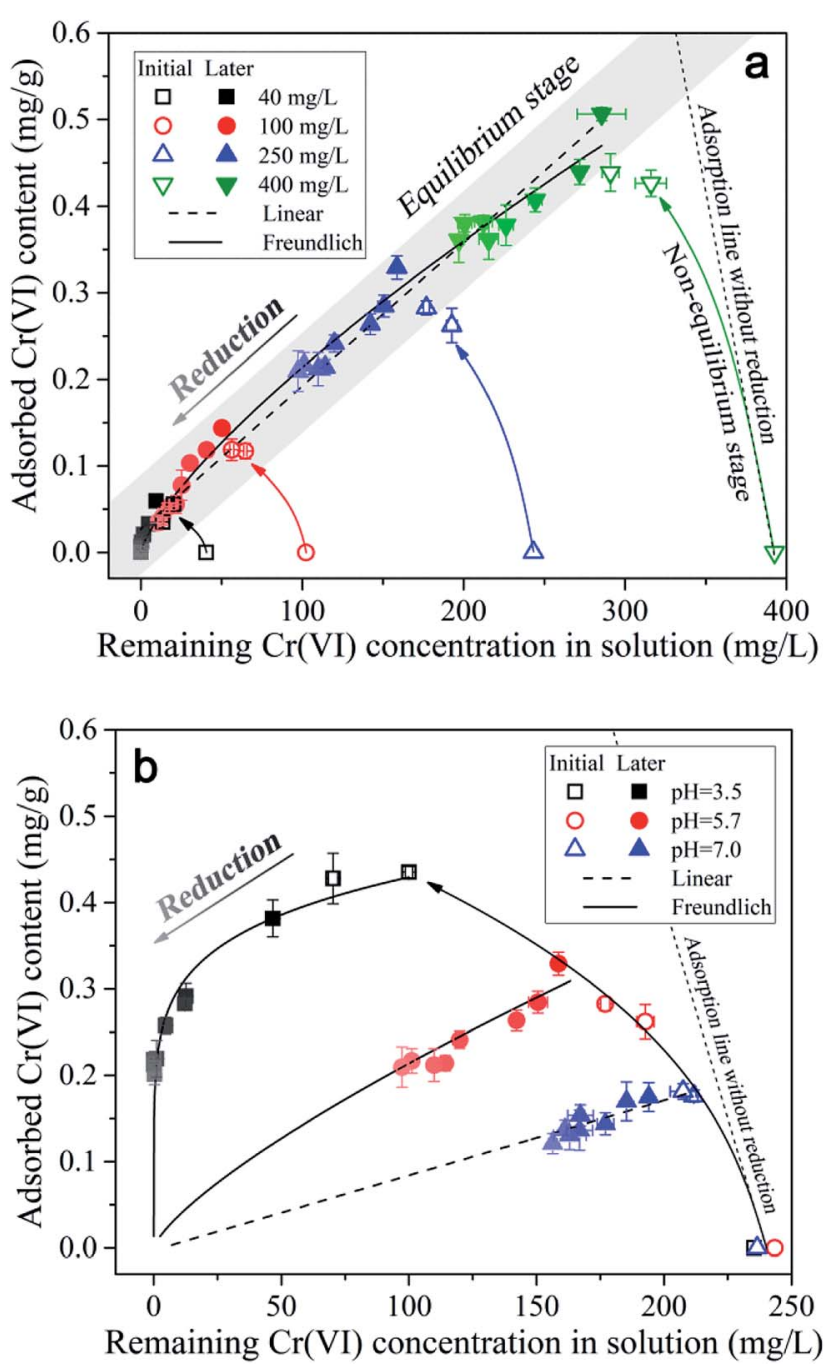

Fig. 5 The partition of $\mathrm{Cr}(\mathrm{vI})$ between solid and aqueous phases in soil environment under (a) different initial concentration and (b) different initial $\mathrm{pH}$ conditions. The labels of initial and later mean the initial stage $(0-30 \mathrm{~d})$ and later stage $(30-240 \mathrm{~d})$ respectively, and the open symbols and solid symbols represent the data points from initial and later stage respectively. The color shade of the symbols from dark to light represents the data points from $30 \mathrm{~d}$ to $240 \mathrm{~d}$, during which the $\mathrm{Cr}(\mathrm{VI})$ was progressively reduced into $\mathrm{Cr}(\mathrm{III})$ in the reaction system. 
point in the diagram as indicated by the color shade from dark to light, and this was mainly induced by the $\mathrm{Cr}(\mathrm{vI})$ losing in the reaction system resulting from $\mathrm{Cr}(\mathrm{vI})$ reduction. Notably, throughout the reduction process of $\mathrm{Cr}(\mathrm{vI})$, the adsorbed $\mathrm{Cr}(\mathrm{vI})$ content on soil particles kept almost a constant ratio (partition coefficient) in respect to the remaining $\mathrm{Cr}(\mathrm{vI})$ concentration in solution, which indicated that the adsorption rate of $\mathrm{Cr}(\mathrm{vI})$ was much more higher than the reduction rate.

Additionally, it can be found in Fig. 5a that the open symbols representing the data points from initial stage $(0-30 \mathrm{~d})$ were a little deviated from the solid symbols representing the data points from later stage (30-240 d), especially for the symbols of higher initial $\mathrm{Cr}(\mathrm{vI})$ concentrations. As mentioned above, the content of adsorbed $\mathrm{Cr}(\mathrm{vI})$ on solid phase increased within 30 $\mathrm{d}$ as shown in Fig. 2, which was not consistent with the decreasing trend of $\mathrm{Cr}(\mathrm{vI})$ concentration in solution. This indicated that the equilibrium state of $\mathrm{Cr}(\mathrm{vI})$ adsorption from aqueous phase to solid phase has not been reached in $30 \mathrm{~d}$, and thus this period can be called the non-equilibrium stage. The short dash line (adsorption line) in the figure reflected the nonequilibrium stage of $\mathrm{Cr}(\mathrm{vI})$ adsorption without $\mathrm{Cr}(\mathrm{vI})$ reduction in theory, where the increasing of adsorbed $\mathrm{Cr}(\mathrm{vI})$ content on solid phase was accompanied by the linear decrease of remaining $\mathrm{Cr}(\mathrm{vI})$ concentration in solution. However, in this experiment a part of $\mathrm{Cr}(\mathrm{vI})$ was reduced into $\mathrm{Cr}$ (III) in the nonequilibrium stage, therefore, the real adsorption line was a little deviated from the theoretical line without reduction.

The data points from equilibrium stage were selected to be fitted by the linear and Freundlich isotherm models as shown in Fig. 5a, and the equations and fitting parameters are listed in Table S1. $\dagger$ It was found that both of the two models had a good performance in the data fitting, and the Freundlich model $\left(R^{2}=\right.$ 0.99) fitted the data a little better compared with the linear model $\left(R^{2}=0.98\right)$. As indicated, the adsorption of $\mathrm{Cr}(\mathrm{vI})$ followed a near-linear partition rule within the initial $\mathrm{Cr}(\mathrm{vI})$ concentration of $400 \mathrm{mg} \mathrm{L}^{-1}$, and this implied that the adsorption capacity of $\mathrm{Cr}(\mathrm{vI})$ by the soil under $\mathrm{pH} 5.7$ had not been reached yet. The maximum $\mathrm{Cr}(\mathrm{vI})$ adsorption quantity of $0.51 \mathrm{mg} \mathrm{g}^{-1}$ was reached under the initial $\mathrm{Cr}(\mathrm{vI})$ concentration of $400 \mathrm{mg} \mathrm{L}^{-1}$ by $30 \mathrm{~d}$, and the partition coefficient $\left(K_{\mathrm{d}}\right)$ was determined to be $0.0017 \mathrm{~L} \mathrm{~g}^{-1}$ according to the fitting results of the linear model. Notably, the intercept of the linear model was not zero $\left(0.027 \mathrm{mg} \mathrm{g}^{-1}\right)$, and this was mainly induced by the non-linear character under low remaining $\mathrm{Cr}(\mathrm{vI})$ concentrations in solution ranging from 0 to $50 \mathrm{mg} \mathrm{L}^{-1}$, where the local partition coefficient was much higher than that under higher $\mathrm{Cr}(\mathrm{vI})$ concentrations.

The partitioning of $\mathrm{Cr}(\mathrm{vI})$ between aqueous and solid phases under different $\mathrm{pH}$ conditions is shown in Fig. 5b. It can be seen that with $\mathrm{pH}$ decreasing the data points can be fitted by the nonlinear Freundlich model better compared with the linear model (the fitting parameters can be found in the Table S2 $\dagger$ ), and the reason may be that the maximum adsorption capacity was almost reached under lower $\mathrm{pH}$ conditions resulting from the saturation of complexation sites. Notably, as the repulsion force between $\mathrm{Cr}(\mathrm{vI})$ anions and negatively charged soil particles decreased with $\mathrm{pH}$ decreasing from 7.0 to 3.5 , the maximum adsorption capacity was expected to be increased with $\mathrm{pH}$ decreasing. However, when the remaining $\mathrm{Cr}(\mathrm{vI})$ concentration in solution was greater than $323 \mathrm{mg} \mathrm{L}^{-1}$, the adsorption amount of $\mathrm{Cr}(\mathrm{vI})$ under $\mathrm{pH} 3.5$ was not larger than that under $\mathrm{pH} 5.7$ according to the extrapolation results of Freundlich model. Considering that the soil particle was negatively charged under the experimental $\mathrm{pH}$ condition $(\mathrm{ZPC}=2.49)$, according to the electrical double layer theory, the diffusion layer will be compressed with $\mathrm{pH}$ decreasing from 7.0 to 3.5, which will decrease the ion exchangeable capacity of the soil particles, and this may account for the decreasing of $\mathrm{Cr}(\mathrm{vI})$ adsorption capacity under $\mathrm{pH}$ 3.5.

In addition, it can be seen in Fig. $5 \mathrm{~b}$ that the data points from initial stage (0-30 d) under $\mathrm{pH} 3.5$ and 7.0 were not deviated from the line of isotherm adsorption model like that under $\mathrm{pH}$ 5.7, and this indicated that the $\mathrm{Cr}(\mathrm{vI})$ adsorption equilibrium state had been reached within $5 \mathrm{~d}$ under $\mathrm{pH} 3.5$ and 7.0. This might be mainly determined by the relationship between adsorption rate and reduction rate of $\mathrm{Cr}(\mathrm{vI})$. Under $\mathrm{pH} 3.5$, the repulsion force between $\mathrm{Cr}(\mathrm{vI})$ anions and negatively charged soil particles was much lower compared with $\mathrm{pH}$ 5.7, as a result, the $\mathrm{Cr}(\mathrm{vI})$ adsorption rate was far higher than its reduction rate, resulting in the fast accumulation of $\mathrm{Cr}(\mathrm{vI})$ on soil particles. While, under $\mathrm{pH}$ 7.0, the proton concentration was far lower compared with that under $\mathrm{pH}$ 5.7, as a result, the $\mathrm{Cr}(\mathrm{vI})$ reduction rate was much lower than its adsorption rate, leading to the fast accumulation of $\mathrm{Cr}(\mathrm{vI})$ on soil particles as well. Under $\mathrm{pH}$ 5.7, the adsorption rate and reduction rate were comparable, therefore, the non-equilibrium stage will last longer.

3.3.2 $\mathrm{Cr}(\mathrm{vI})$ reduction by the black soil. The relationship between adsorption and reduction of $\mathrm{Cr}(\mathrm{vI})$ is the key point to reveal the mechanism of $\mathrm{Cr}(\mathrm{vI})$ retention by black soil. The reduction of $\mathrm{Cr}(\mathrm{vI})$ on soil particles was supposed to follow two possible mechanisms, namely adsorption-reduction mechanism and reduction-adsorption mechanism. ${ }^{35}$ The adsorption-reduction mechanism means that the $\mathrm{Cr}(\mathrm{vI})$ in solution is firstly adsorbed onto soil particles, and then the adsorbed $\mathrm{Cr}(\mathrm{vI})$ is reduced into $\mathrm{Cr}(\mathrm{III})$ on soil particles. The reduction-adsorption mechanism means that the $\mathrm{Cr}(\mathrm{vI})$ is firstly reduce into $\mathrm{Cr}(\mathrm{III})$ in solution, and then the reduced $\mathrm{Cr}$ (III) is adsorbed onto soil particles.

In respect to the reducing agent for $\mathrm{Cr}(\mathrm{VI})$ reduction, $\mathrm{Fe}(\mathrm{II})$, $\mathrm{S}$ (II) and SOM were considered as the main electron donors in soil environment. However, the iron element in the soil mainly existed in trivalent form according to the XRD characterization result (Fig. S8 $\dagger$ ), and the content of sulfur element in the soil only accounted for $0.163 \%(\mathrm{w}: \mathrm{w}$ ) according to the element analysis result. Consequently, the SOM was considered as the main electron donors for $\mathrm{Cr}(\mathrm{vI})$ reduction, which accounted for $11.64 \%$ of the black soil mass. In order to illustrate the changes of humus in soil induced by $\mathrm{Cr}(\mathrm{vI})$ reduction, the humic acid (HA) fraction, which is the majority and most active component of humus in soil for $\mathrm{Cr}(\mathrm{vI})$ reduction, was extracted from the soil samples after reacting with $\mathrm{Cr}(\mathrm{vI})$ for $240 \mathrm{~d}$ at different initial $\mathrm{Cr}(\mathrm{vI})$ concentration and different $\mathrm{pH}$ conditions, and then FTIR spectroscopy was utilized to determine the functional groups variation (shown in Fig. S15 $\dagger$ ). As indicated, the absorbance bands can be found at the bands of 1720, 1639, 1384, 1230 and 
$1031 \mathrm{~cm}^{-1}$, which can be attributed to carboxyl, carbonyl, methyl, phenol and hydroxyl respectively. ${ }^{36-43}$ Because the methyl has been determined to be relatively resistant to $\mathrm{Cr}(\mathrm{vI})$ oxidation, ${ }^{\mathbf{4 4 5}}$ the ratios of absorbances at other functional groups bands to the absorbance of methyl were used to indicate the variation of carboxyl, carbonyl, phenol and hydroxyl, and the results are shown in Fig. S16 and S17. $\dagger$ As indicated, compared with the blank control group (without $\mathrm{Cr}(\mathrm{vI})$ ), the ratio of carboxyl, carbonyl, phenol and hydroxyl to methyl decreased significantly with $\mathrm{pH}$ deceasing and initial $\mathrm{Cr}(\mathrm{vI})$ concentration increasing, especially phenol and carboxyl, which have been determined to act as the main electron donor and complexation site for $\mathrm{Cr}(\mathrm{vI})$ respectively in our previous studies. ${ }^{44}$

Considering that the maximum TOC concentration in solution was about $110 \mathrm{mg} \mathrm{C} \mathrm{L}^{-1}$, which only accounted for less than $2 \%$ of the mass of SOM, therefore, the reduction of $\mathrm{Cr}(\mathrm{VI})$ in solution by DOM can be neglected. This implied that the reduction of $\mathrm{Cr}(\mathrm{vI})$ mainly occurred on the soil particles, meaning that the retention of $\mathrm{Cr}(\mathrm{vI})$ by black soil more tended to follow the adsorption-reduction mechanism.

Additionally, if the retention of $\mathrm{Cr}(\mathrm{vI})$ by black soil followed the adsorption-reduction mechanism, the $\mathrm{Cr}(\mathrm{vI})$ reduction rate in the reaction system should be related to the content of adsorbed $\mathrm{Cr}(\mathrm{vI})$ on soil particles. In order to verify this speculation, a correlation analysis was conducted between the adsorbed $\mathrm{Cr}(\mathrm{vI})$ amount on soil particles and $\mathrm{Cr}(\mathrm{VI})$ reduction rate in the reaction system, and the results were shown in Fig. S9. $\uparrow$ As indicated, a strong positive correlation $\left(R^{2}=0.99\right)$ was found between them, where the $\mathrm{Cr}(\mathrm{vI})$ reduction rate proportionally increased with adsorbed $\mathrm{Cr}(\mathrm{vI})$ content increasing, resulting from the increasing initial $\mathrm{Cr}(\mathrm{vI})$ concentration, and this further confirmed that the $\mathrm{Cr}(\mathrm{vI})$ retention by the black soil followed the adsorption-reduction mechanism.

In order to verify whether the adsorbed $\mathrm{Cr}(\mathrm{vI})$ content also positively correlated with $\mathrm{Cr}(\mathrm{vI})$ reduction rate under various $\mathrm{pH}$ conditions, the corresponding correlation analysis was conducted, and the results were shown in Fig. S10. $\dagger$ As indicated, however, a poor linear correlation $\left(R^{2}=0.85\right)$ was found between them, where a relatively high reduction rate was achieved with a relatively low adsorbed $\mathrm{Cr}(\mathrm{vI})$ content under $\mathrm{pH}$ 3.5. This might be mainly induced by the much higher proton concentration in the reaction system under $\mathrm{pH} 3.5$ compared with that under higher $\mathrm{pH}$ conditions, because the proton participated in the reduction of $\operatorname{Cr}(\mathrm{vI})$ as well. On the other hand, with $\mathrm{pH}$ decreasing from 7.0 to 3.5 , the anion species of $\mathrm{Cr}(\mathrm{vI})$ changed from $\mathrm{CrO}_{4}{ }^{2-}$ to $\mathrm{HCrO}_{4}{ }^{-}$as shown in Fig. S11, $\dagger$ and the corresponding standard electrode potential increased from $-0.13\left(\mathrm{CrO}_{4}{ }^{2-} / \mathrm{Cr}^{3+}\right)$ to $1.33 \mathrm{~V}\left(\mathrm{HCrO}_{4}{ }^{2-} / \mathrm{Cr}^{3+}\right)$ resulting in the increasing of $\mathrm{Cr}(\mathrm{vI})$ oxidizability.

Additionally, under the experimental condition of this study, the reduced $\mathrm{Cr}(\mathrm{III})$ content on soil particles can reached as high as $2.16 \mathrm{mg} \mathrm{g}^{-1}$, while the maximum adsorbed $\mathrm{Cr}(\mathrm{vI})$ content on soil particles was only $0.38 \mathrm{mg} \mathrm{g}^{-1}$. This implied that the $\operatorname{Cr}(\mathrm{vI})$ reduction played a much more important role compared with $\mathrm{Cr}(\mathrm{vI})$ adsorption in $\mathrm{Cr}(\mathrm{vI})$ retention by the black soil. However, the adsorption is equally important in this process, because it directly determines the environmental risk and leaching potential of $\mathrm{Cr}(\mathrm{vI})$ in soils.

\subsection{Modeling of $\mathrm{Cr}(\mathrm{v})$ retention}

According to the analysis above, the retention of $\mathrm{Cr}(\mathrm{vI})$ by black soil was determined to follow the adsorption-reduction mechanism, and this process can be described by the following twostep interface reactions as has been conceptualized by Laidler: ${ }^{\mathbf{4 6}}$

Step one: adsorption of $\mathrm{Cr}(\mathrm{vI})$ from aqueous phase to solid phase

$$
\text { soil }+\mathrm{Cr}(\mathrm{VI}) \rightleftharpoons \text { soil- } \mathrm{Cr}(\mathrm{VI})
$$

Step two: reduction of adsorbed $\mathrm{Cr}(\mathrm{VI})$ into $\mathrm{Cr}(\mathrm{III})$

$$
\text { soil- } \mathrm{Cr}(\mathrm{VI})+\mathrm{H}^{+}+\mathrm{e}^{-} \rightarrow \text { soil- } \mathrm{Cr}(\mathrm{III})+\mathrm{H}_{2} \mathrm{O}
$$

where, soil-Cr(vi) and soil-Cr(III) represent the adsorbed $\mathrm{Cr}(\mathrm{VI})$ and $\mathrm{Cr}(\mathrm{III})$ on soil particles.

Accordingly, a two-step adsorption-reduction kinetic model for $\mathrm{Cr}(\mathrm{vI})$ retention by black soil was developed, the development processes of which can be found in the ESI, $\dagger$ and the model can be described by the following differential equations:

$$
\begin{gathered}
\frac{\mathrm{d} C_{\mathrm{t}}}{\mathrm{d} t}=-k_{1}\left(C_{\mathrm{t}}-\frac{q_{\mathrm{s}}}{K_{\mathrm{d}}}\right) \\
\frac{\mathrm{d} q_{\mathrm{s}}}{\mathrm{d} t}=-k_{2} q_{\mathrm{s}}+\frac{V}{m} k_{1}\left(C_{\mathrm{t}}-\frac{q_{\mathrm{s}}}{K_{\mathrm{d}}}\right) \\
\frac{\mathrm{d} q_{\mathrm{re}}}{\mathrm{d} t}=k_{2} q_{\mathrm{s}}
\end{gathered}
$$

where, $C_{\mathrm{t}}$ represents the $\operatorname{Cr}(\mathrm{vI})$ concentration in solution, $\mathrm{mg} \mathrm{L}{ }^{-1} ; q_{\mathrm{s}}$ represents the adsorbed $\mathrm{Cr}(\mathrm{vI})$ content on soil particles, $\mathrm{mg} \mathrm{g}^{-1} ; q_{\text {re }}$ represents the reduced $\mathrm{Cr}(\mathrm{III})$ in the reaction system by per unit mass of soil, $\mathrm{mg} \mathrm{g}^{-1} ; k_{1}$ represents the adsorption rate constant of $\mathrm{Cr}(\mathrm{vI})$ from solution onto soil particles, dimensionless; $k_{2}$ represents the reduction rate constant of $\mathrm{Cr}(\mathrm{vI})$ in the reaction system, dimensionless; $K_{\mathrm{d}}$ represents the partition coefficient between soil particles and solution, $\mathrm{L} \mathrm{g}^{-1} ; \mathrm{V} / \mathrm{m}$ represents the ratio of solution volume to soil mass.

The kinetic experimental data of $\mathrm{Cr}(\mathrm{vI})$ retention by the black soil under different initial $\mathrm{Cr}(\mathrm{vI})$ concentrations and $\mathrm{pH}$ conditions were simulated using the 1stOpt software by optimizing the parameters of $k_{1}, k_{2}$ and $K_{\mathrm{d}}$ from eqn (3)-(5), and the fitting results and optimized parameters are respectively shown in Fig. 6 and Table 1. As indicated in Fig. 6, the experimental data can be fitted better by the two-step kinetic model under different initial $\mathrm{Cr}(\mathrm{vI})$ concentrations and $\mathrm{pH}$ conditions compared with the traditional first or second order kinetic models (the fitting results by first and second order kinetic models are shown in Fig. S12 and Table S3†).

As can be seen in Table 1 , the optimized $K_{\mathrm{d}}$ of condition (c) and (d) were both $0.0018 \mathrm{~L} \mathrm{~g}^{-1}$, which was consistent with the result $\left(0.0017 \mathrm{~L} \mathrm{~g}^{-1}\right)$ of linear correlation between adsorbed $\mathrm{Cr}(\mathrm{vI})$ content and remaining $\mathrm{Cr}(\mathrm{VI})$ concentration in solution 

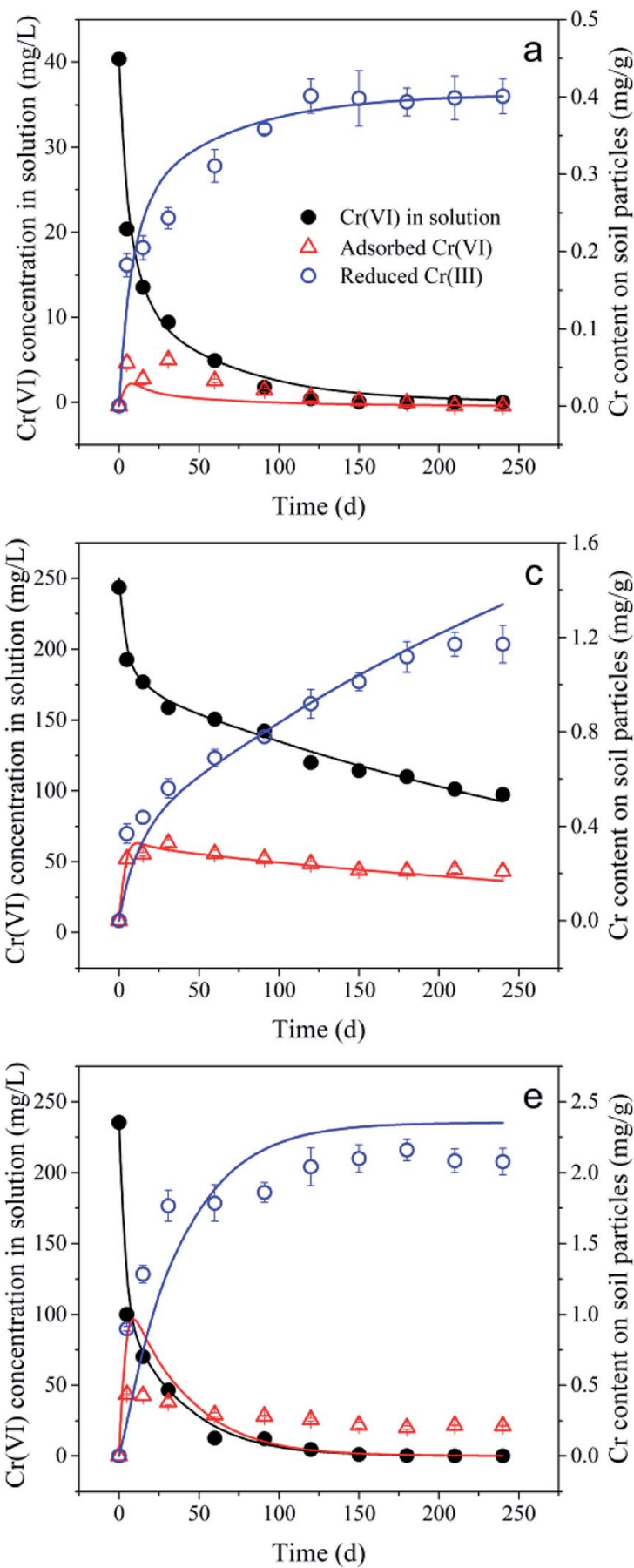
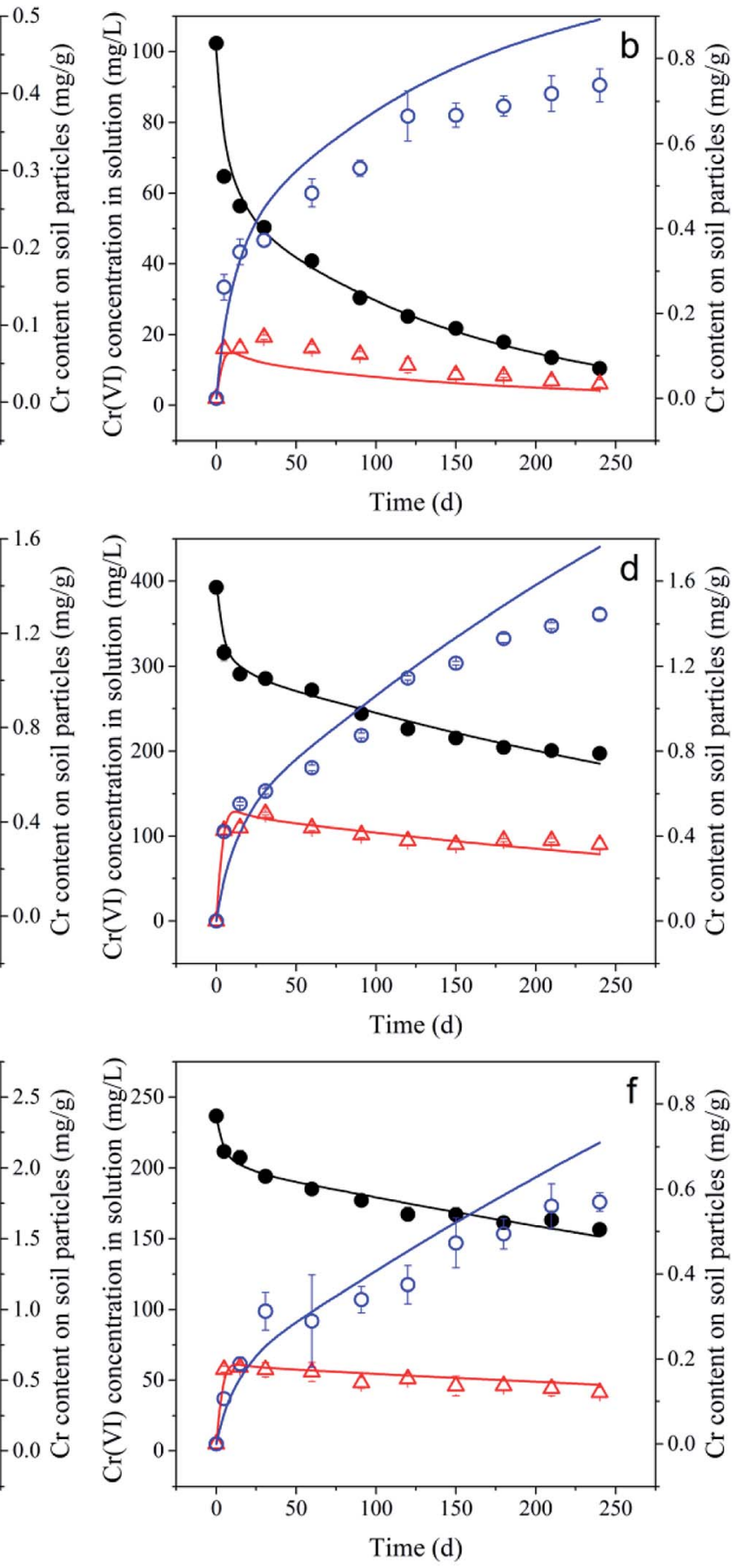

Fig. 6 The time evolution of $\mathrm{Cr}(\mathrm{VI})$ concentration in solution, adsorbed $\mathrm{Cr}(\mathrm{VI})$ content and reduced $\mathrm{Cr}(\mathrm{III})$ content under different initial $\mathrm{Cr}$ (VI) concentration and $\mathrm{pH}$ conditions. The curves are the fitting results of the two-step adsorption-reduction kinetic model. (a-d) represent the fitting results of initial $\mathrm{Cr}(\mathrm{VI})$ concentration ranging from 40 to $400 \mathrm{mg} \mathrm{L}^{-1}$ under $\mathrm{pH}$ 5.7. (e) and (f) represent the fitting results of initial $\mathrm{pH} 3.5$ and 7.0 under initial $\mathrm{Cr}(\mathrm{vI})$ concentration of $250 \mathrm{mg} \mathrm{L}^{-1}$.

under different initial $\mathrm{Cr}(\mathrm{vI})$ concentrations, and the optimized $K_{\mathrm{d}}$ of condition (f) was $0.0009 \mathrm{~L} \mathrm{~g}^{-1}$, which was also consistent with the correlation result $\left(0.0009 \mathrm{~L} \mathrm{~g}^{-1}\right)$. However, the optimized $K_{\mathrm{d}}$ of condition (a) and (b) were found to be a little larger than that of condition (c) and (d), and this was mainly induced by the non-linear partition characteristic under low remaining $\mathrm{Cr}(\mathrm{vI})$ concentrations in solution ranging from 0 to $50 \mathrm{mg} \mathrm{L}^{-1}$ as mentioned before.
It can be found that the optimized $k_{1}$ was much higher than the optimized $k_{2}$, and this indicated that the $\mathrm{Cr}(\mathrm{vI})$ adsorption rate was much higher than its reduction rate, which further confirmed that the reduction of $\mathrm{Cr}(\mathrm{vI})$ was the rate limiting step of $\mathrm{Cr}(\mathrm{vI})$ retention by the black soil. Additionally, the optimized $k_{2}$ value of reduction rate constant was found to be much higher than that in theory $\left(0.0138 \mathrm{~d}^{-1}\right)$ obtained from the correlation slope between $\mathrm{Cr}(\mathrm{vI})$ reduction rate and adsorbed $\mathrm{Cr}(\mathrm{vI})$ content, 
Table 1 Optimized parameters of the two-step adsorption-reduction kinetic model under different initial $\mathrm{Cr}(\mathrm{VI})$ concentrations and pH conditions

\begin{tabular}{llllll}
\hline Condition & $\begin{array}{l}\mathrm{Cr}(\mathrm{vI}) \\
\text { concentration }\left(\mathrm{mg} \mathrm{L}^{-1}\right)\end{array}$ & $\mathrm{pH}$ & $K_{\mathrm{d}}\left(\mathrm{L} \mathrm{g}^{-1}\right)$ & $k_{1}\left(\mathrm{~d}^{-1}\right)$ & $k_{2}\left(\mathrm{~d}^{-1}\right)$ \\
\hline $\mathrm{a}$ & 40 & 5.7 & 0.0060 & 50.6394 & 0.1138 \\
$\mathrm{~b}$ & 100 & 5.7 & 0.0044 & 52.8358 & 0.0626 \\
$\mathrm{c}$ & 250 & 5.7 & 0.0018 & 54.5005 & 0.0994 \\
$\mathrm{~d}$ & 400 & 5.7 & 0.0018 & 55.2086 & 0.0708 \\
$\mathrm{e}$ & 250 & 3.5 & 0.0100 & 12.4845 & 0.0660 \\
$\mathrm{f}$ & 250 & 7.0 & 0.0009 & 59.9781 & 0.85 \\
& & & & & 0.95 \\
& & & & & 0.94 \\
\hline
\end{tabular}

and this might be mainly induced by the fast reduction of $\mathrm{Cr}(\mathrm{vI})$ within $5 \mathrm{~d}$. As various electron donors may exist in the soil environment, and the one with higher reducibility will be consumed by $\mathrm{Cr}(\mathrm{vI})$ preferentially, resulting in the stepwise feature of $\mathrm{Cr}(\mathrm{VI})$ reduction. While the reduction rate constant in theory was determined only by the correlation in the range from 5 to $120 \mathrm{~d}$, therefore, the kinetic model with multiple reduction constants associated with the reducibility of different electron donors might be of significance in the following studies.

In addition, the majority of the optimized $k_{1}$ values ranged from 50 to $60 \mathrm{~d}^{-1}$ except for that under condition (e), and this might be mainly induced by the disproportionate relationship between the adsorbed $\mathrm{Cr}(\mathrm{vI})$ content and remaining $\mathrm{Cr}(\mathrm{vI})$ concentration in solution, which led to the poor fitting result under this reaction condition. It can be seen in Fig. 6e that a significant amount of adsorbed $\mathrm{Cr}(\mathrm{vI})$ still persisted on the soil particles, when the remaining concentration of $\mathrm{Cr}(\mathrm{vI})$ in solution has been very low. This indicated a specific adsorption of $\mathrm{Cr}(\mathrm{vI})$ that was isolated from the electron donors might have occurred on the soil particles, and it cannot be simulated well by the current two-step kinetic model, the underlying mechanism of which still deserved to be further investigate.

\section{Conclusions}

In this study, the adsorption and reduction of $\mathrm{Cr}(\mathrm{vI})$ retention by a typical black soil were investigated respectively by the batch experiment. A near-linear partition law was found between the adsorbed $\mathrm{Cr}(\mathrm{vI})$ content and remaining $\mathrm{Cr}(\mathrm{vI})$ concentration in solution under $\mathrm{pH}$ 5.7, which can be well fitted by both of the linear $\left(R^{2}=0.98\right)$ and Freundlich model $\left(R^{2}=0.99\right)$. With $\mathrm{pH}$ decreasing, the partition showed a strong non-linear feature, which can be described by the Freundlich model better. Additionally, the adsorbed $\mathrm{Cr}(\mathrm{vI})$ was considered as the intermediate state for $\mathrm{Cr}(\mathrm{vI})$ reduction, and the reduction rate was positively correlated with the adsorbed $\mathrm{Cr}(\mathrm{vI})$ content. Therefore, the retention of $\mathrm{Cr}(\mathrm{vI})$ by black soil was determined to follow the adsorption-reduction mechanism, and the two-step kinetic model was proposed accordingly. The two-step kinetic model has a much better fitting performance compared with traditional first and second order kinetic models, and this further implied the reliability of the proposed adsorption-reduction mechanism of $\mathrm{Cr}(\mathrm{vI})$ retention by black soil. The findings of this study will contribute to the understanding and modeling of the $\mathrm{Cr}(\mathrm{vI})$ migration and transformation in soil environment.
However, the influences of $\mathrm{Cr}(\mathrm{vI})$ non-linear partition feature under different $\mathrm{pH}$ conditions, various electron donors with different reducibility, and $\mathrm{Cr}(\mathrm{vI})$ specific adsorption isolated with electron donors on the adsorption-reduction kinetic model still need to be further studied. Additionally, the release mechanism of $\mathrm{Cr}$ (III) may be another topic that deserves to be further investigated as well.

\section{Conflicts of interest}

There are no competing interests to declare.

\section{Acknowledgements}

This work was financially supported by the National Natural Science Foundation of China (41672239), China Geological Survey (1212011121173), and National Science and Technology Major Project (2016ZX05040-002-003).

\section{References}

1 B. Dhal, H. N. Thatoi, N. N. Das and B. D. Pandey, J. Hazard. Mater., 2013, 250-251, 272-291.

2 G. Choppala, N. Bolan and B. Seshadri, J. Hazard. Mater., 2013, 261, 718-724.

3 J. Liu, X. H. Zhang, H. Tran, D. Q. Wang and Y. N. Zhu, Environ. Sci. Pollut. Res., 2011, 18, 1623-1632.

4 K. Dermentzis, A. Christoforidis, E. Valsamidou, A. Lazaridou and N. Kokkinos, Global NEST J., 2011, 13, 412-418.

5 C.-L. Hsu, S.-L. Wang and Y.-M. Tzou, Environ. Sci. Technol., 2007, 41, 7907-7914.

6 E. Tassi, M. Grifoni, F. Bardelli, G. Aquilanti, S. La Felice, A. Iadecola, P. Lattanzi and G. Petruzzelli, Environ. Sci.: Processes Impacts, 2018, 20, 965-976.

7 I. Aharchaou, J. S. Py, S. Cambier, J. L. Loizeau, G. Cornelis, P. Rousselle, E. Battaglia and V. Dal, Environ. Toxicol. Chem., 2017, 37, 983-992.

8 P. M. Jardine, M. A. Stewart, M. O. Barnett, N. T. Basta, S. C. Brooks, S. Fendorf and T. L. Mehlhorn, Environ. Sci. Technol., 2013, 47, 11241-11248.

9 B. Yousaf, G. Liu, Q. Abbas, R. Wang, H. Ullah, M. M. Mian and A. Rashid, RSC Adv., 2018, 8, 25983-25996. 
10 M. M. Mian, G. Liu, B. Yousaf, B. Fu, H. Ullah, M. U. Ali, Q. Abbas, M. A. M. Munir and L. Ruijia, Chemosphere, 2018, 208, 712-721.

11 X. Zhang, J. Tong, B. X. Hu and W. Wei, Environ. Sci. Pollut. Res., 2018, 25, 459-468.

12 T. Mpouras, M. Chrysochoou and D. Dermatas, J. Contam. Hydrol., 2017, 197, 29-38.

13 J. Jiang, Y. Wang, R. Xu and C. Yang, Environ. Earth Sci., 2011, 66, 1155-1162.

14 H. B. Bradl, J. Colloid Interface Sci., 2004, 277, 1-18.

15 S. Butera, S. Trapp, T. F. Astrup and T. H. Christensen, J. Hazard. Mater., 2015, 298, 361-367.

16 G. Choppala, N. Bolan, A. Kunhikrishnan, W. Skinner and B. Seshadri, Environ. Sci. Pollut. Res., 2015, 22, 8969-8978.

17 J. Zhang, H. L. Yin, B. Samuel, F. Liu and H. H. Chen, RSC Adv., 2018, 8, 3522-3529.

18 M. Otero, L. Cutillas-Barreiro, J. C. Novoa-Munoz, M. AriasEstevez, M. J. Fernandez-Sanjurjo, E. Alvarez-Rodriguez and A. Nunez-Delgado, Solid Earth, 2015, 6, 373-382.

19 G. Choppala, A. Kunhikrishnan, B. Seshadri, J. H. Park, R. Bush and N. Bolan, J. Geochem. Explor., 2018, 184, 255260.

20 S. S. Fan, Y. Wang, Y. Li, J. Tang, Z. Wang, J. Tang, X. D. Li and $\mathrm{K} . \mathrm{Hu}, \mathrm{RSC} A d v ., 2017,7,7576-7590$.

21 A. H. Whitaker, J. Pena, M. Amor and O. W. Duckworth, Environ. Sci.: Processes Impacts, 2018, 20, 1056-1068.

22 L. Leita, A. Margon, A. Pastrello, I. Arcon, M. Contin and D. Mosetti, Environ. Pollut., 2009, 157, 1862-1866.

23 J. Zhang, L. Chen, H. Yin, S. Jin, F. Liu and H. Chen, Environ. Pollut., 2017, 225, 86-92.

24 M. K. Banks, A. P. Schwab and C. Henderson, Chemosphere, 2006, 62, 255-264.

25 P. M. Jardine, S. E. Fendorf, M. A. Mayes, I. L. Larsen, S. C. Brooks and W. B. Bailey, Environ. Sci. Technol., 1999, 33, 2939-2944.

26 M. T. Fernández-Pazos, B. Garrido-Rodriguez, J. C. NóvoaMuñoz, M. Arias-Estévez, M. J. Fernández-Sanjurjo,
A. Núñez-Delgado and E. Álvarez, Water, Air, Soil Pollut., 2012, 224, 1366.

27 A. A. Khan, M. Muthukrishnan and B. K. Guha, J. Hazard. Mater., 2010, 174, 444-454.

28 J. Jiang, R. Xu, Y. Wang and A. Zhao, Chemosphere, 2008, 71, 1469-1475.

29 J. Zhang, H. Yin, H. Wang, L. Xu, B. Samuel, F. Liu and H. Chen, Environ. Sci. Pollut. Res., 2018, 25, 16913-16921.

30 S. Lu, W. Tan, F. Liu and X. Feng, Acta Pedol. Sin., 2006, 43, 756-763.

31 S. Lettens, V. B. De, P. Quataert, W. B. Van, B. Muys and O. J. Van, Eurasian J. Soil Sci., 2010, 58, 1244-1253.

32 K. Pyrzynska, TrAC, Trends Anal. Chem., 2012, 32, 100-112.

33 G. Arslan, S. Edebali and E. PehliVan, Desalination, 2010, 255, 117-123.

34 S. Barnie, J. Zhang, H. Wang, H. Yin and H. Chen, Chemosphere, 2018, 212, 209-218.

35 P. Janos, V. Hula, P. Bradnova, V. Pilarova and J. Sedlbauer, Chemosphere, 2009, 75, 732-738.

36 P. E. Fanning and M. A. Vannice, Carbon, 1993, 31, 721-730. 37 N. H. Hsu, S. L. Wang, Y. C. Lin, G. D. Sheng and J. F. Lee, Environ. Sci. Technol., 2009, 43, 8801-8806.

38 J. M. O'Reilly and R. A. Mosher, Carbon, 1983, 21, 47-51.

39 C. Sellitti, J. L. Koenig and H. Ishida, Carbon, 1990, 28, 221228.

40 T. T. Zhao, W. Z. Ge, Y. X. Nie, Y. X. Wang, F. G. Zeng and Y. Qiao, Fuel Process. Technol., 2016, 150, 71-77.

41 W. Chen, N. Habibul, X. Y. Liu, G. P. Sheng and H. Q. Yu, Environ. Sci. Technol., 2015, 49, 2052-2058.

42 Z. Filip, K. Haider, H. Beutelspacher and J. Martin, Geoderma, 1974, 11, 37-52.

43 S. Paim, L. Linhares, A. Mangrich and J. Martin, Biol. Fertil. Soils, 1990, 10, 72-76.

44 J. Zhang, H. Yin, L. Chen, F. Liu and H. Chen, Environ. Pollut., 2018, 237, 740-746.

45 J. Zhang, H. Yin, H. Wang, L. Xu, B. Samuel, J. Chang, F. Liu and H. Chen, Sci. Total Environ., 2019, 651, 2975-2984.

46 K. J. Laidler, Pure Appl. Chem., 1996, 68, 149-192. 